
disease among Japanese living in Hawaii. $\mathcal{N}$ Engl f. Med 1977;297:405-9. Criqui $\mathrm{MH}$. The reduction of coronary heart disease with light to moderate alcohol consumption: effect or artifact? Br f Addict 1990;85:854-7.

23 Mikhailidis DP, Jeremy JY, Barradas MA, et al. Effect of ethanol on rascular prostacylin Jeremy JY, Barradas MA, clal. Ereect of ethanol on rascular release. BMF 1983;287:1495-8.
24 Meade TW, Chakrabarti R, Haines AP, et al. Characteristics affecting fibrinolytic activity and plasma fibrinugen concentrations. B 117 1979: $153-6$

25 MacMahon S. Alcohol consumption and hypertension. Hypertension 1987:9 $111-21$

Accepted 30 April 1991

\title{
Prevalence of primary fibromyalgia in the Finnish population
}

\author{
Matti Mäkelä, Markku Heliövaara
}

\begin{abstract}
Objective-To obtain descriptive epidemiological data on fibromyalgia and its components in a representative sample of the Finnish population.

Design-Cross sectional study of 8000 Finns aged 30 or more invited for screening and a main examination for musculoskeletal disorders and other major disorders.

Setting-A mobile clinic.

Population-7217 subjects who attended the screening phase; 3434 subjects positive on screening who attended the main examination for musculoskeletal disorders.

Main outcome measures-Musculoskeletal, mental, and other symptoms detected by interview and questionnaire; results of standardised clinical examination of the musculoskeletal system; operational definition of fibromyalgia; mortality at 10 years.
\end{abstract}

Results - The prevalence of fibromyalgia was low ( 54 cases; $0.75 \%$ ) and related to age (peak prevalence at 55-64 years), female sex (twice as prevalent in women), occupation (no cases among 1596 white collar professionals), level of education (strong inverse gradient), and high levels of physical stress at work. No significant associations were found with body mass index, smoking, or mental stress at work. The prevalence of fibromyalgia was sensitive to even minor modifications of the definition. Fibromyalgia was strongly coincident with many other disorders, especially musculoskeletal conditions. Fibromyalgia did not predict mortality.

Conclusion-Descriptive epidemiological data offer little support for the concept of fibromyalgia.

\section{Introduction}

Fibromyalgia (sometimes called primary fibromyalgia or fibrositis) has been referred to as an independent disease entity or certainly a syndrome. ${ }^{1}$ It has been claimed to be highly prevalent and frequently misdiagnosed..$^{23}$ Clinical descriptions give the impression that it is often severely disabling, ${ }^{+5}$ but most samples are from referral centres and thus subject to a strong selection bias. To our knowledge no one has examined the prevalence of primary fibromyalgia in the general population.

The Social Insurance Institution in Finland has conducted a mobile clinic survey of the health status of a representative sample of the Finnish population aged 30 and over - the mini-Finland health survey. ${ }^{6}$ In this paper we use these data to report the distribution and mutual correlations of the components of the primary fibromyalgia syndrome in the Finnish population. Our principal aims were to estimate the prevalence of fibromyalgia and detect determinants of its occurrence.

\section{Population and methods}

The data were collected in 1977-80 as part of the mini-Finland health survey, designed to provide infor- mation about the population's health, its need for care and rehabilitation, the consequences of disease, and factors affecting health. ${ }^{6}$ The study population was a two stage cluster sample ${ }^{7}$ of 8000 people $(3637$ men, 4363 women) who were representative of all Finnish adults aged 30 years or more. In the first stage 40 regions (mostly single municipalities, of which there are 461 in Finland) were selected to represent the population of Finland with regard to geographical area, degree of urbanisation, and proportion of people employed in industry and agriculture. In the second stage a sample of inhabitants was drawn systematically from the population register of each region.

The examinations were carried out by the mobile clinic of the Social Insurance Institution in two main phases, a screening phase and a main examination phase. A total of 7217 subjects $(90 \cdot 2 \%$ of the sample) participated in the screening phase. The distributions of sex, age, marital status, and level of education among the participants corresponded closely with those in the whole Finnish population.

\section{FIELD SURVEY}

The screening protocol included several interview items that have been defined as components of the primary fibromyalgia syndrome - namely, reported "hurt all over," enumeration of painful body sites, general fatigue, poor sleep, anxiety and tension, and gastrointestinal problems. The irritable bowel syndrome was not sought specifically. Moderate or severe levels of the symptoms were considered relevant in this study to detect fibromyalgia.

Subjects $(\mathrm{n}=3775 ; 52 \cdot 3 \%)$ who in the screening phase reported any moderate or severe musculoskeletal symptoms or had impaired function of at least one joint were invited to a clinical examination to evaluate musculoskeletal morbidity; $3434(91.0 \%)$ attended. ${ }^{6}$ They were examined by one of the mobile clinic physicians, and all conditions that satisfied preestablished criteria for major musculoskeletal disorders were independently recorded. Although this examination was initially not designed to detect primary fibromyalgia, it included a systematic recording of pressure tenderness in the wrists, elbows, trapezoid muscles, shoulder joints, knee joint region, and Achilles tendons. These represent many but not all of the points suggested in previous studies of fibromyalgia.

Other illnesses were also screened for and were investigated separately by similar diagnostic procedures. Mental disorders were sought by the general health questionnaire ${ }^{89}$ and diagnosed by the present state examination and a computerised coding algorithm (CATEGO-ID). ${ }^{10}$

Deaths among the study population were traced to the end of 1989 by linkage with the Finnish population register. Ascertainment was complete.

\section{DIAGNOSIS OF FIBROMYALGIA}

For most analyses we used an operational definition of fibromyalgia adapted from Yunus et al.' This 
required at least two out of six items of symptom history combined with at least four tender points, or at least three symptom items combined with at least two tender points. Only subjects reporting pain in several

TABLE I-Prevalence of fibromyalgia (Yunus criteria) among Finns aged 30 or more by demographic and other determinants

\begin{tabular}{|c|c|c|c|c|}
\hline Subgroup & No of subjects & $\begin{array}{c}\text { No with } \\
\text { fibromyalgia }\end{array}$ & $\begin{array}{l}\text { Prevalence of } \\
\text { fibromyalgia }\end{array}$ & $\mathrm{p}$ Value \\
\hline All & 7217 & 54 & 0.75 & \\
\hline \multicolumn{5}{|c|}{ 列 } \\
\hline Men & 3322 & 16 & $0.48\}$ & \multirow{2}{*}{$\begin{array}{l}0 \cdot 038 \text { (Adjusted } \\
\text { for age only }{ }^{\star} \text { ) }\end{array}$} \\
\hline Women & 3895 & 38 & $0.98\}$ & \\
\hline \multicolumn{5}{|l|}{ Age (years): } \\
\hline $30-44$ & 2716 & 2 & $0.07)$ & \multirow{5}{*}{$\begin{array}{l}<0.0001 \\
\text { (Adjusted for } \\
\text { sex only }{ }^{\star} \text { ) }\end{array}$} \\
\hline $45-54$ & 1609 & 14 & 0.87 & \\
\hline $55-64$ & 1348 & 19 & $1.41\}$ & \\
\hline $65-74$ & 1078 & 13 & $1 \cdot 21$ & \\
\hline$\geqslant 75$ & 466 & 6 & $1 \cdot 29]$ & \\
\hline \multicolumn{5}{|l|}{ Level of education: } \\
\hline Less than elementary & 736 & 20 & $2 \cdot 721$ & \multirow{4}{*}{$0.0001^{\star}$} \\
\hline Elementary & 4169 & 31 & 0.74 & \\
\hline Secondary & 1506 & 3 & 0.201 & \\
\hline High school or more & 806 & 0 & $0 \mathrm{j}$ & \\
\hline \multicolumn{5}{|l|}{ Occupational class: } \\
\hline Professional & 1596 & 0 & 01 & \multirow{5}{*}{$\begin{array}{c}0.004 \\
\left(\begin{array}{c}\text { Mantel-Haenszel } \\
\left.\text { test }^{\star}\right)\end{array}\right.\end{array}$} \\
\hline Agriculture & 1688 & 25 & 1.48 & \\
\hline Industry & 1743 & 8 & $0.46\}$ & \\
\hline Services & 1811 & 14 & 0.77 & \\
\hline Never employed & 379 & 7 & 1.85 & \\
\hline \multicolumn{5}{|l|}{ Body mass index $\left(\mathrm{kg} / \mathrm{m}^{2}\right)$ : } \\
\hline$<23$ & 1816 & 5 & $0 \cdot 28\}$ & \multirow{6}{*}{$0 \cdot 123^{\star}$} \\
\hline $23-26$ & 2203 & 17 & $0 \cdot 77$ & \\
\hline $27-29$ & 1737 & 15 & 0.86 & \\
\hline $30-32$ & 898 & 13 & 1.45 & \\
\hline $33-35$ & 375 & 3 & 0.80 & \\
\hline$>35$ & 188 & 1 & $0.53\}$ & \\
\hline \multicolumn{5}{|l|}{ Smoking: } \\
\hline Never smoker & 4009 & 31 & $0.77 \mid$ & \multirow{3}{*}{$0 \cdot 127^{\star}$} \\
\hline Ex-smoker & 1505 & 13 & $0.86\}$ & \\
\hline Current smoker & 1703 & 10 & $0.59]$ & \\
\hline \multicolumn{5}{|l|}{ Physical work stress: } \\
\hline Very low & 1895 & 8 & 0.42 & \multirow{3}{*}{$0.031^{\star}$} \\
\hline Intermediate & 1433 & 7 & $0.49\}$ & \\
\hline High & 3889 & 39 & $1 \cdot 00$ & \\
\hline \multicolumn{5}{|l|}{ Mental work stress: } \\
\hline Very low & 2780 & 27 & $0.97 \mid$ & \multirow{3}{*}{$0.99 \star$} \\
\hline Intermediate & 1964 & 8 & 0.41 & \\
\hline High & 2473 & 19 & $0 \cdot 77)$ & \\
\hline
\end{tabular}

*Significance tests (likelihood ratio statistics) of associations based on logistic regression models adjusting for age and sex if not otherwise specified.

TABLE II-Distribution of components of Yunus's criteria for fibromyalgia syndrome among subjects with and without syndrome

\begin{tabular}{|c|c|c|c|c|}
\hline & \multicolumn{2}{|c|}{$\begin{array}{l}\text { Subjects without } \\
\text { fibromyalgia } \\
(n=7163)\end{array}$} & \multicolumn{2}{|c|}{$\begin{array}{l}\text { Subjects with } \\
\text { fibromyalgia } \\
\quad(n=54)\end{array}$} \\
\hline & No & $\%$ & No & $\%$ \\
\hline \multicolumn{5}{|l|}{ Tender points: } \\
\hline Unknown & 3783 & $52 \cdot 8$ & 0 & 0 \\
\hline None & 2343 & $32 \cdot 7$ & 0 & 0 \\
\hline 1 & 708 & 9.9 & 0 & 0 \\
\hline 2 & 197 & $2 \cdot 8$ & 31 & $57 \cdot 4$ \\
\hline 3 & 67 & 0.9 & 15 & $27 \cdot 8$ \\
\hline 4 & 25 & 0.4 & 6 & $11 \cdot 1$ \\
\hline 5 & 21 & 0.3 & 1 & 1.9 \\
\hline 6 & 6 & 0.1 & 0 & 0 \\
\hline 7 & 9 & $0 \cdot 1$ & 1 & 1.9 \\
\hline 8 & 1 & $<0 \cdot 1$ & 0 & 0 \\
\hline 9 & 2 & $<0.1$ & 0 & 0 \\
\hline 10 & 1 & $<0.1$ & 0 & 0 \\
\hline \multicolumn{5}{|l|}{ Painful body regions: } \\
\hline None & 2451 & $34 \cdot 2$ & 0 & 0 \\
\hline 1 & 1759 & $24 \cdot 6$ & 0 & 0 \\
\hline 2 & 1143 & $16 \cdot 0$ & 0 & 0 \\
\hline 3 & 703 & $9 \cdot 8$ & 0 & 0 \\
\hline 4 & 444 & $6 \cdot 2$ & 10 & $18 \cdot 5$ \\
\hline 5 & 257 & $3 \cdot 6$ & 9 & $16 \cdot 7$ \\
\hline 6 & 146 & $2 \cdot 0$ & 9 & $16 \cdot 7$ \\
\hline 7 & 101 & $1 \cdot 4$ & 12 & $22 \cdot 2$ \\
\hline 8 & 71 & $1 \cdot 0$ & 4 & $7 \cdot 4$ \\
\hline 9 & 50 & 0.7 & 6 & $11 \cdot 1$ \\
\hline 10 & 38 & 0.5 & 4 & $7 \cdot 4$ \\
\hline "Hurt all over" & 1388 & $19 \cdot 4$ & 49 & $90 \cdot 7$ \\
\hline General fatigue & 739 & $10 \cdot 3$ & 42 & $77 \cdot 8$ \\
\hline Poor sleep & 428 & 6.0 & 22 & $40 \cdot 7$ \\
\hline Anxiety and tension & 1199 & $16 \cdot 7$ & 30 & 55.6 \\
\hline Abdominal trouble & 776 & $10 \cdot 8$ & 21 & 38.9 \\
\hline \multicolumn{5}{|c|}{ Number of symptom items: } \\
\hline None & 4419 & $61 \cdot 7$ & 0 & 0 \\
\hline 1 & 1505 & $21 \cdot 0$ & 0 & 0 \\
\hline 2 & 709 & $9 \cdot 9$ & 2 & $3 \cdot 7$ \\
\hline 3 & 318 & $4 \cdot 4$ & 30 & 55.6 \\
\hline 4 & 151 & $2 \cdot 1$ & 16 & 29.6 \\
\hline 5 & 57 & 0.8 & 4 & $7 \cdot 4$ \\
\hline 6 & 4 & $0 \cdot 1$ & 2 & $3 \cdot 7$ \\
\hline
\end{tabular}

regions lasting at least three months were included. All subjects with an inflammatory polyarthritis or spondylarthritis were excluded, as were all subjects with painful degenerative joint disorders in the knees, hips, hands, and shoulders (three regions out of four required for exclusion). This was labelled the Yunus set.

The sensitivity of the criteria to modification was investigated by applying three other, slightly modified sets of criteria. Firstly, the Yunus criteria were simplified by requiring a combination of three or more symptom items with three or more tender regions (modified set 1). Secondly, less strict criteria of two or more symptom items and two or more tender regions were applied (modified set 2). Thirdly, generalised pain (count of painful regions exceeding six or the subject reporting moderate or severe pain all over) and three or more tender regions were required, approximating the criteria used by Cathey et $a l^{\beta}$ (modified set 3). An explicit report of longlasting pain was required for the modified criteria and the same conditions excluded as from the Yunus set.

\section{STATISTICAL METHODS}

In addition to simple descriptive tabulation, logistic regression models" were fitted to investigate the association of fibromyalgia with several possible determinants and with other disorders. The $x$ statistic was used to estimate the concordance between the different sets of criteria. Cox's proportional hazards model $^{12}$ was used to assess the effect of fibromyalgia on survival.

\section{Results}

Table I shows the crude prevalence of fibromyalgia according to the Yunus criteria. It also shows the prevalence by sex, age, level of education, present or previous occupation, smoking, body mass index (weight/height ${ }^{2} ; \mathrm{kg} / \mathrm{m}^{2}$ ), and history of physical and mental stress at work (present or previous).

In a multivariate analysis of the possible determinants of fibromyalgia, adjusting for age and sex, only the level of education was significant, overwhelming the associations with occupational class and physical stress at work. The odds ratio associated with education was 0.29 (95\% confidence interval 0.18 to 0.49$)$, referring to the ratio of two adjacent educational levels. Thus the odds ratio contrasting the highest level (3) with the lowest level $(0)$ was $0 \cdot 29^{3}=0 \cdot 024$. This accords with table I, which shows that there were no cases among subjects with a high school or equivalent education and no cases even among the twice larger group of professional white collar employees.

Table II shows the prevalence of symptom items and counts of painful body regions, tender points, and positive symptom items among subjects with and without fibromyalgia. The findings showed no bimodality or any obvious upper level of a nonpathological distribution.

Table III shows that the prevalence of fibromyalgia was highly dependent on the specific configuration of criteria. Applying the modified set 1 led to an even lower prevalence than the Yunus set, and disagreement between any two sets of criteria was high.

Though all criteria excluded chronic conditions giving similar symptoms, morbidity was much higher among the fibromyalgia group than in the rest of the population. Table IV shows that fibromyalgia was associated with a high risk of having a mental disorder, and all subjects fulfilling the criteria for fibromyalgia also fulfilled the criteria for at least one other musculoskeletal disorder (excluding the conditions defined above).

By the end of 1989,12 of the 54 subjects with 
TABLE III-Prevalence of fibromyalgia according to varying sets of criteria, and correspondence ( $x$ statistic) of different sets

\begin{tabular}{|c|c|c|c|c|c|}
\hline & \multirow{2}{*}{$\begin{array}{l}\text { No of } \\
\text { cases }\end{array}$} & \multirow{2}{*}{$\begin{array}{c}\% \\
\text { Prevalence }\end{array}$} & \multicolumn{3}{|c|}{ Correspondence of sets $(x)$} \\
\hline & & & Set 1 & Set 2 & Set 3 \\
\hline Yunus criteria ${ }^{\star}$ & 54 & $0 \cdot 75$ & 0.56 & 0.79 & 0.43 \\
\hline Modified set It & 21 & $0 \cdot 29$ & & $0 \cdot 40$ & 0.57 \\
\hline Modified set $2 \ddagger$ & 83 & $1 \cdot 15$ & & & 0.48 \\
\hline Modified set 30 & 52 & 0.72 & & & \\
\hline
\end{tabular}

All sets-Inflammatory polyarthritis, spondylarthritis, and generalised osteoarthritis excluded. Only subjects with pain lasting at least three months included.

^Yunus's criteria: $(a)$ at least two symptom items and four tender points or (b) at least three symptom items and two tender points.

†Modified set 1: at least three symptom items and three tender points.

$\ddagger$ Modified set 2: at least two symptom items and two tender points.

\$Modified set 3: (a) at least three painful body regions or "hurt all over" and

(b) at least three tender points.

TABLE IV-Prevalence of certain disorders and their relative risks (odds ratios and $95 \%$ confidence intervals), adjusted for age and sex, as determined by fibromyalgia

\begin{tabular}{|c|c|c|c|c|c|}
\hline & \multicolumn{2}{|c|}{$\begin{array}{l}\text { Subjects } \\
\text { without } \\
\text { fibromyalgia } \\
(n=7163)\end{array}$} & \multicolumn{2}{|c|}{$\begin{array}{c}\text { Subjects } \\
\text { with } \\
\text { fibromyalgia } \\
(\mathrm{n}=54)\end{array}$} & \multirow{2}{*}{$\begin{array}{c}\text { Odds ratio }(95 \% \\
\text { confidence } \\
\text { interval) }\end{array}$} \\
\hline & No & $\%$ & No & $\%$ & \\
\hline Osteoarthriti & 1131 & $15 \cdot 8$ & 43 & $79 \cdot 6$ & $15.5(7.5 \mathrm{tc}$ \\
\hline Knee osteoarthritis & 747 & $10 \cdot 4$ & 35 & $64 \cdot 8$ & $11 \cdot 4(6 \cdot 1$ to $21 \cdot 3)$ \\
\hline Hip osteoarthritis & 362 & $5 \cdot 1$ & 7 & & $1.7(0.7$ to 3.8$)$ \\
\hline Hand osteoarthritis & 343 & $4 \cdot 8$ & 9 & $16 \cdot 7$ & $2 \cdot 1(1 \cdot 0$ to $4 \cdot 5)$ \\
\hline Chronic low back pain & 1227 & $17 \cdot 1$ & 26 & $48 \cdot 1$ & $3 \cdot 5(2 \cdot 1$ to $6 \cdot 1)$ \\
\hline Chronic neck pain & 844 & $11 \cdot 8$ & 26 & $48 \cdot 1$ & $4 \cdot 9(2 \cdot 8$ to $8 \cdot 5)$ \\
\hline Shoulder disorder & 409 & $5 \cdot 7$ & 19 & $35 \cdot 2$ & $6 \cdot 1(3.4$ to $10 \cdot 8)$ \\
\hline \multicolumn{6}{|l|}{ Any musculoskeletal } \\
\hline & 2945 & $41 \cdot$ & 54 & $100 \cdot 0$ & Indeterminate \\
\hline Any circulatory disorder & 2053 & $28 \cdot 7$ & 22 & $40 \cdot 7$ & $1.0(0.5$ to 1.7$)$ \\
\hline & 1222 & $17 \cdot 1$ & 15 & $27 \cdot 8$ & $1.9(1.0$ to 3.5$)$ \\
\hline \multirow{2}{*}{$\begin{array}{l}\text { Any other major somatic } \\
\text { disorder }\end{array}$} & & & & & \\
\hline & 1570 & 21.9 & 19 & $35 \cdot 2$ & $1 \cdot 3(0.8$ to $2 \cdot 4)$ \\
\hline Any mental disorder & 1255 & $17 \cdot 5$ & 30 & $55 \cdot 6$ & $4 \cdot 8(2 \cdot 8$ to $8 \cdot 4)$ \\
\hline
\end{tabular}

fibromyalgia had died $(22 \cdot 6 / 1000$ person years) as compared with 1202 of the 7163 subjects without fibromyalgia (16.6/1000 person years). This difference was not significant when adjusted for sex and age in a proportional hazards model (relative risk 0.90 , $\left.\chi^{2}=0 \cdot 14, \mathrm{df}=1, \mathrm{p}=0 \cdot 71\right)$.

\section{Discussion}

A weakness of this study was that fibromyalgic tender points were not tested systematically. Authorities on fibromyalgia cite evidence that the tender point phenomenon is strictly local and not one of a generally lowered pain threshold, ${ }^{2}$ so tender points might easily have been missed by the examiners in our study. The effect would be for us to have underestimated the occurrence of fibromyalgia in the community. The symptom items alone, however, restricted the possible prevalence to $5 \%$, and any tender point criterion was bound to have reduced this down to the range that we observed.

Another question is the number of patients with fibromyalgia who were missed because of a faulty screening procedure. The number of subjects with three or more items of symptom history suggestive of fibromyalgia who did not attend the medical examination and were not excluded by the exclusion criteria was 20 . The positive predictive value of the symptom criterion was $15 \%$ among those attending the medical examination. Therefore, probably not more than four of these would have fulfilled the tender point criterion. Hence faulty screening would not have produced a grossly biased prevalence estimate.

Our results suggest that the prevalence of fibromyalgia in the general population at any given time is very low. This might be due to either a low incidence or a short duration of the disorder. The symptoms and disability associated with fibromyalgia have been claimed to be highly stable over at least a year, ${ }^{5}$ supporting the hypothesis of a low incidence. Moreover, the mean duration of symptom history among patients has been as high as 12 years. ${ }^{3}$ On the other hand, the lower prevalence that we found among elderly as compared with middle aged people suggests that most of these patients eventually either get better or develop some other, more specific disease to account for their symptoms. ${ }^{13}$

We found a strong association of fibromyalgia with a low level of education. In contrast, the patients described by Cathey et al had an educational level above that of the general population. This disparity may have been due to selection bias in the hospital series.

Usually when an association is found between the level of education and an illness it is better explained by variables that are closer to disease causation, such as exposure to occupational hazards. In the case of fibromyalgia no such intervening variables were noted. But this does not mean that deficient education contributes to the development of fibromyalgia in any biological or clinical sense. Possibly the expression of pain varies with the level of education, leading to the gradient in the prevalence that we observed.

The diminished prevalence among the elderly could have been caused by an increased mortality. Also, if some subjects with fibromyalgia later develop serious disorders ${ }^{13}$ we should expect an increased mortality. But we did not observe this. One reason may be that our study base was the general population whereas a series of patients from a referral centre probably includes a high proportion regarded by their primary care physicians as patients who "seem sick."

The fibromyalgia syndrome seems to have no effect on longevity. No theoretical or distributional reasons are evident for its criteria. No description of a specific natural course or specific response to treatment has been reported. The prevalence and distribution in any given study population will be determined not only by the selection of the study base (referred hospital patients, primary health care clients, general population, etc) but also on the arbitrary choice of diagnostic criteria.

Descriptive epidemiological data lend little support to the notion of an independent syndrome of fibromyalgia. Rather, it seems that the extreme ends of the different (although correlated) dimensions of illness, pain, and mental distress sometimes result in such a complex picture of suffering, perhaps as a general response to any of several possible influences. ${ }^{14}$

Two phenomena have been quoted as specific proof of the biological nature of fibromyalgia. These are the local tenderness of the tender points ${ }^{2}$ and an $\alpha$ electroencephalographic sleep anomaly. ${ }^{15}$ Their distribution, correlates, and possible significance in the general population have not been described. These phenomena may equally well be non-specific manifestations of any extreme distress state as components of an independent syndrome.

Fibromyalgia resembles a constellation of stars: its components are real enough but the pattern is in the mind of the beholder. That ancient Greeks gave a group of stars the name of a mythical being is not reason enough to suppose that the constellation has any actual meaning, much less the attributes of the creature.

I Yunus MB, Masi AT, Aldag JC. Preliminary criteria for primary fibromyalgia syndrome (PFS): multivariate analysis of a consecutive series of PFS, other pain patients, and normal subjects. Clin Exp Rheumatol 1989;7:63-9.

2 Campbell SM, Clark S, Tindall EA, Forehand ME, Bennett RM. Clinical characteristics of fibrositis. I. A "blinded," controlled study of symptom and tender points. Arthritis Rheum 1983;26:817-24.

3 Cathey MA, Wolfe F, Kleinheksel SM, Hawley DJ. Socioeconomic impact of fibrositis. A study of 81 patients with primary fibrositis. Am f Med 1986:81 (suppl 3A):78-84.

4 Yunus M, Masi AT, Calabro JJ, Miller KA, Feigenbaum SL. Primary Yunus $M$, Masi AT, Calabro Jj, Miller $K A$, Feigenbaum $S L$. Primary fibromyalgia (fibrositis): clinical study of 50 patien 
- 5 Hawley DJ, Wolfe F, Cathey MA. Pain, functional disability, and psychological status: a 12-month study of severity in fibromyalgia. 7 Rheumatol 1988;15:1551-6.

6 Aromaa A, Heliövaara M, Impivaara $\mathrm{O}$, Knekt $\mathrm{P}$, Maatela J. The execution of the mini-Finland health survey. Part 1. Helsinki, Turku: Social Insurance Institution 1989 ML.88. In Finnish with English summary.

Kish L. Survey sampling. New York: Wiley, 1965.

8 Goldberg D. The detection of psychiatric illness by questionnaire. London: Oxford University Press, 1972. (Maudsley Monograph 21 .)

9 Takala J, Räkköläinen V. Salminen J, Sievers K. Mental health in the middleaged population. Acta Psvchiatr Scand 1979;59:294-305.

10 Wing JK, Cooper JE, Sartorius N. The measurement and classification of psychiatric symptoms. London: Cambridge University Press, 1974.
11 Haberman SJ. Analysis of qualtiative data. Vol 1 . Introductory topics. New York: Academic Press, 1978

12 Cox DR. Regression models and life tables (with discussion). Fournal of the Roval Statistical Society $(B)$ 1972; 74:187-220.

13 Forslind K, Fredriksson E, Nived O. Does primary fibromyalgia exist

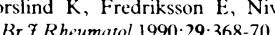

14 Goldenberg DL. Fibromyalgia and other chronic fatigue syndromes: is ther evidence for chronic viral disease? Semin Arthritis Rheum 1988;18:111-20. 15 Moldofsky $\mathrm{H}$. The contribution of sleep-wake physiology to fibromyalgia. In Fricton JR, Awad EA, eds. Advances in pain research and therapy. Vol 17 Myofascial pain and fibromyalgia. New York: Raven Press, 1990.
Winford Orthopaedic Hospital, Bristol Michael J F Fordyce, FRCS, orthopaedic registrar Allen S Baker, FRCs, senior orthopaedic registrar E Gerald Staddon, BSC, medical physicist

Correspondence to: Mr M J F Fordyce, Royal Cornwall Hospital (City),

Truro, Cornwall TR1 2HZ.

BMf 1991;303:219-20

\title{
Efficacy of fixed minidose warfarin prophylaxis in total hip replacement
}

\author{
Michael J F Fordyce, Allen S Baker, Gerald E Staddon
}

\section{Abstract}

Objective-To determine whether a small fixed perioperative dose of warfarin would prevent deep vein thrombosis after total hip replacement.

Design-Prospective, randomised, double blind placebo controlled trial.

Setting-Winford Orthopaedic Hospital, Bristol.

Subjects -148 patients having primary total hip replacement.

Intervention-Warfarin $1 \mathrm{mg}$ given daily for one week before and three weeks after surgery.

Main outcome measure-Deep vein thrombosis diagnosed by the iodine-125 labelled fibrinogen uptake method.

Results-Deep vein thrombosis occurred in 25 $34 \%)$ of the patients given warfarin and $19(26 \%)$ of the controls (difference $8 \% ; 95 \%$ confidence interval $-6 \cdot 8 \%$ to $22 \cdot 8 \%$ )

Conclusion-Fixed minidose warfarin does not prevent deep vein thrombosis after total hip replacement.

\section{Introduction}

The incidence of thromboembolism is particularly high after total hip replacement. Deep vein thrombosis occurs in up to $70 \%$ of patients. ${ }^{1}$ The incidence of the postphlebitic limb syndrome complicating thrombosis after hip replacement is unknown but may be as high as $51 \%$, which occurs after long bone fractures. ${ }^{2}$ Subclinical pulmonary emboli occur in up to $23 \%$ of patients, ${ }^{3}$ and $1-2 \%$ of patients die of pulmonary embolism.

Many prophylactic regimens have been described but none have proved ideal and there is no consensus on the most suitable prophylaxis. ${ }^{5}$ Several studies found that low dose heparin was effective, ${ }^{67}$ but Sikorski et al suggested that this regimen may only delay the onset of thromboembolic complications, describing a rebound surge in thromboembolism once heparin was stopped. ${ }^{8}$ Other studies found low dose heparin to be ineffective. ${ }^{910}$ Conventional ful dose anticoagulation begun before surgery is highly effective in preventing thromboembolism ${ }^{11}$ but has never been widely accepted because of the risks. ${ }^{4}$

A recent report of the success of fixed minidose warfarin in gynaecological patients ${ }^{12}$ prompted us to test its efficacy after total hip replacement. The advantages of this simple regimen were that there were no haemorrhagic complications; prescription was by a daily fixed dose; and prophylaxis was continued after discharge from hospital, covering the period when $60 \%$ of fatal pulmonary emboli are likely to occur. ${ }^{11}$

\section{Patients and methods}

The study was modelled on projected estimations from the report of Poller et al. ${ }^{12}$ We were seeking to detect a reduction in deep vein thrombosis from $50 \%$ to $20 \%$. For the power of the study $(1-\beta)$ to reach $90 \%$ we required 75 patients in each group.

One hundred and forty eight patients who were having primary total hip replacement were randomly allocated to either the treatment group or the control group. The treatment group received $1 \mathrm{mg}$ warfarin daily for one week before and three weeks after surgery. The control group received placebo for the same period. Randomisation was achieved by the use of random number tables by the hospital pharmacy, which prepared the tablets in foil packets. Thus neither the patients nor the investigators were aware of which group the patient was in. Prothrombin time, activated partial thromboplastin time, platelet count, and haemoglobin concentration were assessed at two weeks and at 24 hours preoperatively and 48 hours postoperatively. Patients were excluded if there was a history of thromboembolism or a medical contraindication to warfarin. Smoking history was not recorded. All patients gave fully informed consent.

All the hip arthroplasties were performed in the lateral decubitus position by either the posterior or direct lateral approach. Patients received a standardised general anaesthetic. Wounds were closed with subcuticular suture. Two $6 \mathrm{~mm}$ suction drains were used. Intraoperative blood loss was estimated and postoperative drainage and the volume of blood transfused were recorded.

Diagnosis of deep vein thrombosis-All patients were screened for deep vein thrombosis by the iodine-125 labelled fibrinogen uptake method..$^{113}$ The thyroid was protected by oral potassium iodide ( $100 \mathrm{mg}$ daily). Each patient received $3.7 \mathrm{MBq}(100 \mu \mathrm{Ci}){ }^{125} \mathrm{I}$-fibrinogen on the morning after surgery. Daily scanning of radioactivity at nine points ${ }^{13}$ on both legs ${ }^{10}$ was performed either until discharge or until two weeks postoperatively. Deep vein thrombosis was diagnosed in the calf or popliteal veins when the ${ }^{125} I$-fibrinogen count was raised by at least $20 \%$ over one or more points and this increase persisted over two consecutive days. Any suspected thrombosis in the femoral vein was further investigated by phlebography as postoperative haematoma may cause a false positive increase in radioactivity in that region. Patients with thrombosis in the popliteal vein or more proximally received full anticoagulant treatment.

Wound complications-All wounds were inspected and scored clinically at one week. Wounds were judged to be clean, moist, or inflamed. Haematomas were sought with a real time ultrasound machine with a 